\title{
A Brief Review on Structural Health Monitoring Sensor Technology in Civil and Aviation Technology Applications
}

\author{
${ }^{1}$ Faculty of Mechanical and Manufacturing Engineering, \\ Universiti Tun Hussein Onn Malaysia, Parit Raja, Johor, 86400, MALAYSIA \\ ${ }^{2}$ Structural Integrity and Monitoring Research Group (SIMReG), \\ Universiti Tun Hussein Onn Malaysia, Parit Raja, Johor, 86400, MALAYSIA \\ ${ }^{3}$ Center of Excellence Geopolymer \& Green Technology (CeGeoGTech), \\ Universiti Malaysia Perlis (UniMAP), Kangar, Perlis, 01000, MALAYSIA \\ *Corresponding Author
}

Ahmad Hamdan Ariffin ${ }^{1,2,3 *}$, Zaleha Mohamad ${ }^{1,2}$, Shahruddin Mahzan ${ }^{1,2}$

DOI: https://doi.org/10.30880/jamea.2020.02.01.001

Received 30 August 2020; Accepted 01 November 2020; Available online 30 November 2020

\begin{abstract}
The Structural Health Monitoring (SHM) system is a method for evaluating and monitoring the integrity of the structure. It has been widely used in various engineering sectors, such as in aerospace, civil and energy sectors due to its ability to react to structural changes on an online basis or in real-time monitoring. The SHM system was able to evolve and work in a variety of structures or components due to the rapid development of sensor technology. It is believed that SHM will become an important tool in various industries for structural monitoring in future years. The paper presents a summary of the latest SHM technology in civil and aviation technology applications as well as the challenges in cost analysis and certification issues for the implementation of SHM.
\end{abstract}

Keywords: Structural health monitoring, structural integrity, aerospace, civil, transportation, cost analysis

\section{Introduction}

Structural integrity is a crucial aspect that is related to safety. Environmental stress is the common factor attributed to the defect in structure. Therefore, periodically inspection is conducted to monitor the condition of the structure. However, identifying and assessing the extent of internal damage, and its precise location can be very challenging. Hence, structural health monitoring (SHM) system application is proposed due to the advantages in giving real-time data [1], [2] as compared to the Non-Destructive Test (NDT) which is conducted offline [3]. SHM involves continuous observation of structural integrity over a period of time by using an array of connected sensors during the duration of the service life of the structure [1], [3], [4]. The possible problems or damage could be detected earlier prior to structural damage. SHM can reduce any cost due to catastrophic failure and reduce the human resources cost for inspection. Besides that, SHM is capable of recognizing the best solution to maintain a structure and to extend its design life [5].

SHM can be divided into two aspects, which are passive response and active response. Condition monitoring is one of the passive response techniques in SHM [6]. The periodical response received will be compared to the normal (default) data to determine if there are any changes in the signal, which take effect from the structure's integrity such as shafts, motors and wind turbine blades [7]. Meanwhile, the active response will monitor the signal, and feedback to the system if the signal changes from the natural signal.

The technology of SHM is enhanced from time to time. However, the technology adoption in industrial application still lacking due to the confidence level of the system robustness in real application [8][9]. Nevertheless, the improvement 
was conducted on various aspects such as sensing and sensor, signaling processing algorithm and storage [10]-[12]. The application also has been employed widely at various sectors in composite [13]-[18], energy [19]-[21], civil industry [19], [22] and aviation industry [12], [22]-[25]. Hence, this paper reports a general insight of SHM in civil and aviation application. Besides that, a brief discussion on sensor technology is presented as well. The sensor technology that widely use in SHM such as strain-based method [6], [12], [18], [26], Eddy current [27], guided waves [23], [28]-[32], acoustic emission [33]-[35]. and carbon nanotubes (CNT) [36].

\section{Civil structure application}

The important of SHM can be discovered from Taiwan's Nanfang'ao bridge tragedy in 2011 where the bridge collapsed. No early warning sign was obtained from the structure to indicate a structural defect. The investigation reported that the possible failure was caused by rust, wear and tear [37]. The application of SHM may prevent such bad tragedy by providing early detection warning, monitoring the structural health and can save human life. E. Gasparin et al. [27] reported the importance of Eddy current sensor in monitoring the bridge structure. The study also proposed several improvements for future investigation such as matrix design elements to permit a device blind positioning, the accuracy of crack length optimization and online algorithms integration for fatigue life assessment [27]. SHM was employed in Manhattan bridge, New York City where it was reported that the bridge floor beams were subjected to induce distortion and cracks due to repetition of train loads. The sensor selected base on guided waves sensor concept. Over 20 accelerometers were installed on the bridge beam to investigate the structural integrity correlation with the trainloads. The results show that the joints misalignment and train wheel sounds impacting the end of the rails. Therefore, further action was conducted via SHM system installation that can monitor the potential of fatigue cracking directly and induced distortion on the rail structure [28]. From this SHM application, the structural integrity of the bridge can be preserved in the long-run, and the life-cycle maintenance cost can be reduced. Furthermore, a comparison between strain gauge and optical fiber sensor for concrete beam was conducted to detect any crack propagation under a three-point bending setup as shown in Fig. 1. Optical fiber sensor was reported to increase the method accuracy considerably. Hence, reducing the crack width errors for cracks beyond $0.2 \mathrm{~mm}$ [29].

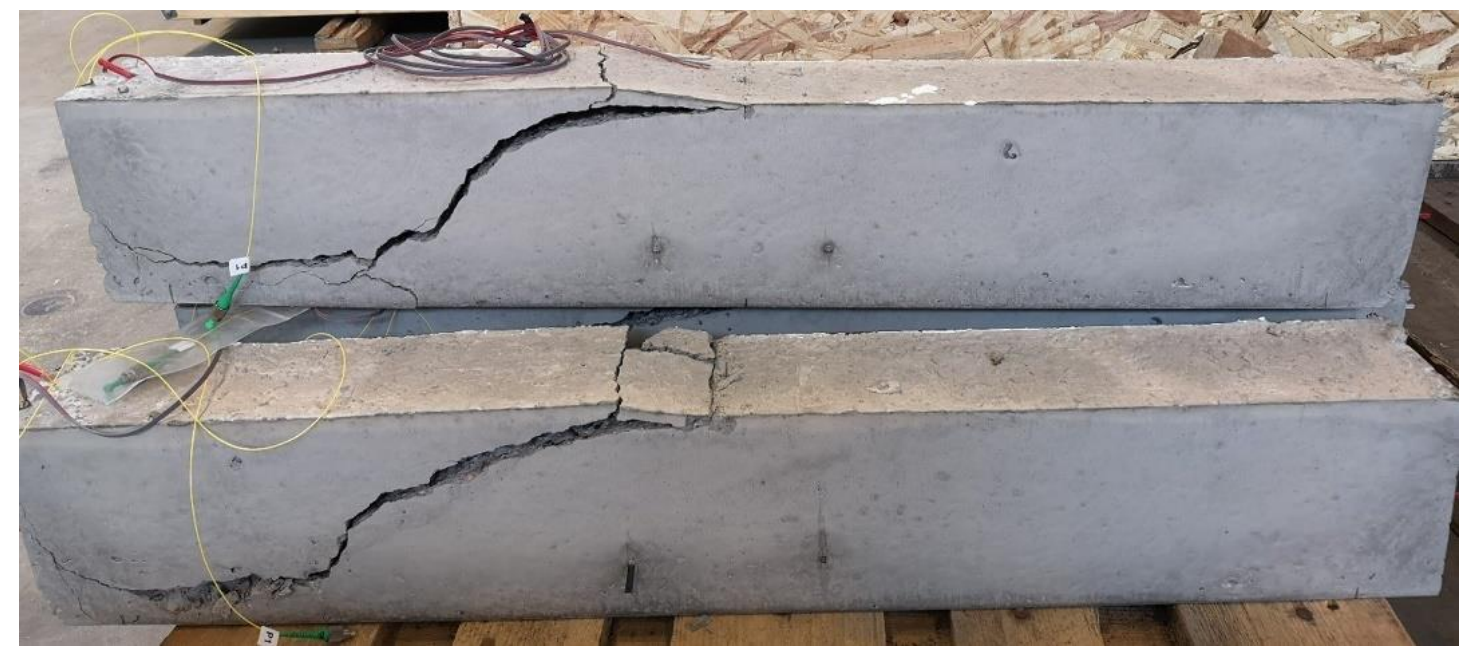

Fig. 1 - Concrete beam specimens after testing. The shear failure mechanism occurs [29]

The application of SHM in wind turbine systems is gaining serious attention as well. In the ultrasonic guided waves approach, the lower excitation frequencies show a more consistent performance across all sensor paths of the 9-meter CX-100 wind turbine rotor blade in a controlled fatigue-test environment [30], [31]. The application of macro fiber composite (MFC) was employed as a sensor to monitor the structural integrity of a kenaf turbine blade for wind turbine via a strain-based method. Interestingly, the sensor also performs as a micro energy harvester [6].

SHM applications have also been explored to investigate the impact damage for kenaf fiber composite [18]. 10 Piezoelectric sensor arrays (PZT) sensors were used to capture the strain wave propagation. Then an effective impact damage classification procedure was established using a multilayer perceptron (MLP) neural network. The result showed that by using the strain profiles as inputs feature, it gave the high classification rate for all classes assigned except minimum peak feature get the lowest classification rate which is below $90 \%$. While in other research, PZT sensors also have been used to investigate the wave propagation in woven pineapple fiber [26]. A series of 30 low-velocities, lowenergy impacts were performed at the position assigned. The two-second sampling of resulting strain waves measurement was recorded using 12 PZT sensors. The result indicated that the time of arrival is almost found similar for all the sensors, but the maximum amplitudes are different. The nearer the sensor to the impact location, the higher the maximum amplitude. The wave velocity characteristics provide substantial data prior to impact localization and characterizations. 
Understanding on the behavior and damage characteristics is vital to evaluate current conditions and estimate their integrity for future application.

The application of SHM in civil structures had shown significant enhancement. Most of the discussion and analysis was conducted on the bridge, and concrete analysis as these elements will involve human life. The summary of sensor or method applications are summarized in Table 1.

Table 1 - Structural health monitoring sensor or method in the civil structure application

\begin{tabular}{lcc}
\hline Type of sensor/ method & Application & Reference \\
\hline Accelerometer & Bridge -floor beams & {$[28]$} \\
Strain gauges & Bridge, Concrete beam & {$[28],[29]$} \\
Crack gauges & Bridge & {$[28]$} \\
Optical fiber sensor & Concrete beam & {$[29]$} \\
Macro Fiber Composite & Wind turbine blade & {$[4],[6]$} \\
Ultrasonic guided wave & Wind turbine blade & {$[30],[31]$} \\
Piezoelectric sensor arrays (PZT) & Composite structure, pipeline & {$[17],[18],[26],[38],[39]$} \\
Eddy current sensor & Bridge, Concrete beam & {$[27]$} \\
\hline
\end{tabular}

\section{Aviation industry application}

Damage structure can be invisible inside a structure. It also cannot be seen via visual observation due to the early stage of cracks or damage. SHM technology is capable of detecting possible structural flaws, although the surface may appear smooth and undamaged.

The advantage element of SHM is real-time monitoring. A lamb wave is also able to determine the undamaged, damaged and repaired characteristic of carbon fibre reinforced plastic (CFRP) laminate [32]. CFRP is replacing aluminum alloys as the primary and secondary structure for newly developed aircraft such as the Boeing 787 and Airbus A350. The research reports that the intervals of interest were selected using Morlet wavelet analysis to evaluate the Condition Structural Index (CSI) and the Amplitude Based Assessment (ABA) for each condition. Next, the results were characterised using principal component analysis (PCA) to distinguish the characteristic - undamaged, damaged and repaired [32]. A case study between comparative vacuum monitoring (CVM) and lamb wave (LW) technique was compared in the Embraer-190 flight test aircraft [25]. Both SHM techniques show better detection as compared to NDT technique. The process of collecting data was expedited, and the damage information was presented precisely [25]. Another application of SHM in aviation is Fibre Bragg grating (FBG) sensors, as one of optical fiber strain sensor which is embedded inside aerospace-grade composite material [12]. The research was conducted to evaluate the robustness of sensors embedded technique in producing the SHM signal and perform the monitoring function. The tests were conducted following the aerospace standards, in terms of temperature cycling, pressure cycling, exposure to humidity, hydraulic fluid and fatigue loading. The results show that the FBG embedded technique was applicable for SHM strategies in aerospace-grade composite material. Further comparison on CVM, FBG and Piezoelectric wafer active sensors (PWAS) were conducted to evaluate the ability of the sensors to detect the smallest damage size [23]. CVM was proposed as the best choice due to the capability to detect any damage up to $0.02 \%$.

On top of that, aircraft airframe is vulnerable to corrosion, potentially leading to material degradation, and eventually causing fatigue cracks. Generally, aircraft structures are well coated. However, the aircraft is exposed to various types of impact and damage during daily services. Three methods are available to monitor and measure corrosion. The first method involves direct measurement of corrosion effects using electrochemical sensors such as Electrochemical Impedance Spectroscopy (EIS) sensor. The second method involves measurement of the corrosivity environment, where the corrosive condition of underlying structures is evaluated. For example, galvanic sensors are used to monitor the corrosion of metallic elements through the changes in electrical resistance of the sensor. The third method involves the measurement of corrosion using chemical sensors [20][36]. This sensor can detect the presence of specific ions from a corroded component/structure. However, the reliability of the sensor is still questionable since it could not demonstrate long-term stability or resistance to poisoning caused by contaminants.

Besides that, Acoustic Emission (AE) is another technique in SHM used to detect and inspect the cracks development or any leakage in a structure. Generally, the structural problem is due to several factors, such as stress corrosion, creep, and fatigue [33]. AE operates at a frequency range above the audible sound frequency between 150 and $300 \mathrm{kHz}$. This technique has great potential for aerospace composite structures [34][35]. Table 2 summarizes the application of structural health monitoring sensor in the aviation industry. 
Table 2 - Structural health monitoring sensor in the aviation application

\begin{tabular}{llc}
\hline Type of sensor & \multicolumn{1}{c}{ Application } & Reference \\
\hline Electrochemical Impedance Spectroscopy (EIS) sensor & Aviation & {$[20]$} \\
Galvanic sensors & Aviation & {$[20]$} \\
Chemical sensors & Aviation & {$[20]$} \\
Piezoelectric wafer active sensor (PWAS) - ultrasonic waves. & Aircraft panel & {$[23]$} \\
Acoustic Emission (AE) & Aerospace composite & {$[33]$} \\
& structure & {$[23],[25]$} \\
Comparative vacuum monitoring (CVM) & Aircraft panel & {$[25]$} \\
Lamb wave (LW) & & {$[12],[23]$} \\
Optical fiber strain sensor- Fibre Bragg grating (FBG) sensors, & Aerospace composite & \\
& structure & \\
\hline
\end{tabular}

\section{Challenges in SHM implementation}

Generally, SHM applications show a positive impact in the long run both in safety and maintenance cost. However, system costing is the most influencing criteria in the SHM implementation. The crucial factors that are calculated in the cost analysis include sensor cost, installation cost, inspection cost, cost caused by extra weight, cost reduction due to less number of labor and discount due to maintenance downtime reduction [23]. The maintenance cost can be reduced significantly, as compared to the current traditional NDT while sustaining the level of risk [40]. The technology and installation of this system may incur a higher cost due to the increased amount of sensors installed (depends on aircraft size), and well beyond the affordability of many small and medium industries [23]. Besides that, the implementation of SHM in aircraft industry requires authority approval, multiple testing conditions and weight penalty, which could prolong the implementation process in the aircraft industry. Hence, this guidance may assist the industry in deciding and planning the application of SHM in its technical operation. The engineers must verify specific parameters that are highly likely to affect structural integrity so that only necessary sensors are used instead of using multiple sensors to measure all sorts of parameters.

A study concluded that corrosion sensor is not cost-effective and that the current ground inspection of aircraft is already sufficient, for now, to detect corrosion [21]. However, the application of corrosion sensor is much more costeffective in hard to access areas such as undersea/subterranean pipelines and offshore structures [38]. Next was on the interpretation of the test result. Since the SHM enables real-time monitoring, the size of the data collected can be enormous. It is very challenging for engineers to analyze and interpret big data. A special set of skills is needed to utilize the data to facilitate decision-making [23]. Hence, Industrial Revolution 4.0 is the key factors to improve the data collection, process, interpretation and action taken to the particular structure.

Another challenge is that SHM employment is certification to conduct the SHM system on the aircraft. The system should perform a strict and rigid assessment to prove that the system can endure such an environmental situation. Federal Aviation Regulations AC-21-16D is the reference to obtain the certification from the authority [23].

\section{Conclusion}

This paper discusses advances in the use of various sensors complementing the SHM applications in both civil and aviation industries. A variety of sensors and integrated sensor networks are available to evaluate the performance of the desired system, including structural elements, electronics, hydraulics, avionics and others. Smaller size matters in the advent of sensor technology, as innovators continue to minimize the size of sensors to enable embedding in various structures and remote locations. It is essential for engineers to determine crucial parameters and analyze the big data to gauge structural integrity and performance. It is important to verify where to measures, and translate the data obtained into useful information in the decision-making process in order to optimize the maintenance process. It is also crucial to select the desired sensor based on its usage and ascertain if it is practical and effective in obtaining reliable data that are free from noise disturbance.

\section{Acknowledgement}

The authors would like to thank the Universiti Tun Hussein Onn Malaysia (UTHM) and CeGeoGTech for their support and encouragement to complete this research.

\section{References}

[1] M. Mitra and S. Gopalakrishnan, "Guided wave-based structural health monitoring: A review," Smart Materials and Structures. 2016, doi: 10.1088/0964-1726/25/5/053001

[2] A. H. Ariffin, M. T. H. Sultan, F. Bin Mustapha, A. U. M. Shah, and S. N. A. Safri, "Potential of structural health monitoring and micro energy harvester system for VAWT," Int. J. Recent Technol. Eng., 2019

[3] D. Adams, J. White, M. Rumsey, and C. Farrar, "Structural health monitoring of wind turbines: method and 
application to a HAWT," Wind Energy, vol. 14, no. 4, pp. 603-623, 2011, doi: 10.1002/we.437

[4] A. Hamdan, F. Mustapha, K. A. Ahmad, A. S. Mohd Rafie, M. R. Ishak, and A. E. Ismail, "The bonded macro fiber composite (MFC) and woven kenaf effect analyses on the micro energy harvester performance of kenaf plate using modal testing and Taguchi method," J. Vibroengineering, vol. 18, no. 2, 2016

[5] C. C. Ciang, J.-R. Lee, and H.-J. Bang, "Structural health monitoring for a wind turbine system: a review of damage detection methods," Meas. Sci. Technol., vol. 19, no. 12, 2008, doi: 12200110.1088/09570233/19/12/122001

[6] A. Hamdan, F. Mustapha, and M. T. H. Sultan, "The macro-fibre composite-bonded effect analysis on the microenergy harvester performance and structural health-monitoring system of woven kenaf turbine blade for vertical axis wind turbine application," Adv. Mech. Eng., 2018, doi: 10.1177/1687814018802046

[7] A. Hamdan, F. Mustapha, K. A. Ahmad, and A. S. Mohd Rafie, "A review on the micro energy harvester in Structural Health Monitoring (SHM) of biocomposite material for Vertical Axis Wind Turbine (VAWT) system: A Malaysia perspective," Renew. Sustain. Energy Rev., vol. 35, 2014, doi: 10.1016/j.rser.2014.03.050

[8] A. Güemes, A. Fernandez-Lopez, A. R. Pozo, and J. Sierra-Pérez, "Structural Health Monitoring for Advanced Composite Structures: A Review,” J. Compos. Sci., 2020, doi: 10.3390/jcs4010013

[9] P. Cawley, "Structural health monitoring: Closing the gap between research and industrial deployment," Struct. Heal. Monit., 2018, doi: 10.1177/1475921717750047

[10] H. Salehi and R. Burgueño, "Emerging artificial intelligence methods in structural engineering," Eng. Struct., vol. 171, no. November 2017, pp. 170-189, 2018, doi: 10.1016/j.engstruct.2018.05.084

[11] C. Tuloup, W. Harizi, Z. Aboura, Y. Meyer, K. Khellil, and R. Lachat, "On the use of in-situ piezoelectric sensors for the manufacturing and structural health monitoring of polymer-matrix composites: A literature review," Compos. Struct., vol. 215, no. February, pp. 127-149, 2019, doi: 10.1016/j.compstruct.2019.02.046

[12] S. Goossens et al., "Aerospace-grade surface-mounted optical fibre strain sensor for structural health monitoring on composite structures evaluated against in-flight conditions," Smart Mater. Struct., vol. 28, no. 6, 2019, doi: $10.1088 / 1361-665 X / a b 1458$

[13] J. Karger-Kocsis, H. Mahmood, and A. Pegoretti, "All-carbon multi-scale and hierarchical fibers and related structural composites: A review,” Compos. Sci. Technol., vol. 186, no. October 2019, 2020, doi: 10.1016/j.compscitech.2019.107932

[14] S. C. Brown, C. Robert, V. Koutsos, and D. Ray, "Methods of modifying through-thickness electrical conductivity of CFRP for use in structural health monitoring, and its effect on mechanical properties - A review," Compos. Part A Appl. Sci. Manuf., vol. 133, no. March, p. 105885, 2020, doi: 10.1016/j.compositesa.2020.105885

[15] A. Technology, "Victor Thierry - The need for Structural Health Monitoring ( SHM ) for composite structures About Victor Thierry," pp. 1-7, 2020

[16] M. Torres, "Parameters' monitoring and in-situ instrumentation for resin transfer moulding: A review," Compos. Part A Appl. Sci. Manuf., vol. 124, no. February, p. 105500, 2019, doi: 10.1016/j.compositesa.2019.105500

[17] Z. Mohamad et al., "Classification of damage severity in natural fibre composites using principal component analysis," Int. J. Integr. Eng., vol. 10, no. 8, pp. 147-152, 2018, doi: 10.30880/ijie.2018.10.08.023

[18] M. Zaleha, S. Mahzan, and I. M. Izwana, "Damage Size Classification of Natural Fibre Reinforced Composites Using Neural Network," in Advanced Materials Research, 2014, doi: 10.4028/www.scientific.net/AMR.911.60

[19] H. Wang, A. Jasim, and X. Chen, "Energy harvesting technologies in roadway and bridge for different applications - A comprehensive review," Appl. Energy, vol. 212, no. August 2017, pp. 1083-1094, 2018, doi: 10.1016/j.apenergy.2017.12.125

[20] L. Ziegler, E. Gonzalez, T. Rubert, U. Smolka, and J. J. Melero, "Lifetime extension of onshore wind turbines: A review covering Germany, Spain, Denmark, and the UK," Renew. Sustain. Energy Rev., vol. 82, no. January 2017, pp. 1261-1271, 2018, doi: 10.1016/j.rser.2017.09.100

[21] Y. Du, S. Zhou, X. Jing, Y. Peng, H. Wu, and N. Kwok, "Damage detection techniques for wind turbine blades: A review," Mech. Syst. Signal Process., vol. 141, p. 106445, 2020, doi: 10.1016/j.ymssp.2019.106445

[22] R. Yao and S. N. Pakzad, "Autoregressive statistical pattern recognition algorithms for damage detection in civil structures,” Mech. Syst. Signal Process., vol. 31, pp. 355-368, 2012, doi: 10.1016/j.ymssp.2012.02.014

[23] T. Dong and N. H. Kim, "Cost-effectiveness of structural health monitoring in fuselage maintenance of the civil aviation industry," Aerospace, vol. 5, no. 3, 2018, doi: 10.3390/aerospace5030087

[24] I. Lopez and N. Sarigul-Klijn, "A review of uncertainty in flight vehicle structural damage monitoring, diagnosis and control: Challenges and opportunities," Prog. Aerosp. Sci., vol. 46, no. 7, pp. 247-273, 2010, doi: 10.1016/j.paerosci.2010.03.003

[25] F. Dotta et al., "SHM qualification process and the future of aircraft maintenance," 31st Congr. Int. Counc. Aeronaut. Sci. ICAS 2018, pp. 1-7, 2018

[26] A. Info, "Exploiting the Wave Characteristics in Natural Fibre Reinforced Composites for Passive Damage Evaluation," Aust. J. Basic Appl. Sci., vol. 9, no. 8, pp. 22-28, 2015

[27] E. Gasparin, G. Santi, and A. Nussbaumer, "Eddy Current Crack Monitoring System for Structural Health 
Monitoring (SHM) Applications," 68th Int. Inst. Weld. Annu. Assem. Int. Conf, pp. 1084-1090, 2018

[28] K. McAnulty, "Structural Health Monitoring of Representative Cracks in the Manhattan Bridge," The State University of New Jersey, 2020

[29] C. G. Berrocal, I. Fernandez, and R. Rempling, "Crack monitoring in reinforced concrete beams by distributed optical fiber sensors," Struct. Infrastruct. Eng., pp. 1-16, Feb. 2020, doi: 10.1080/15732479.2020.1731558

[30] M. A. Rumsey and J. A. Paquette, "Structural Health Monitoring of Wind Turbine Blades," Proc. SPIE, vol. 6933, 2008

[31] S. G. Taylor et al., "Incipient crack detection in composite wind turbine blades," in Advances in Structural Health Management and Composite Structures 2012, 2012

[32] K. D. Mohd Aris, F. Mustapha, S. M. Sapuan, and D. L. Majid, “A condition structural index (CSI) using principal component analysis (PCA) for normal, damage and repair conditions of CFRP laminate," in Advances in Structural Health Management and Composite Structures 2012, 2012

[33] A. Fahr, Aeronautical Applications of Non-destructive Testing. 2014

[34] B. Raj, T. Jayakumar, and M. Thavasimuthu, Practical Non-destructive Testing. 2002

[35] H. Mei, M. F. Haider, R. Joseph, A. Migot, and V. Giurgiutiu, "Recent advances in piezoelectric wafer active sensors for structural health monitoring applications," Sensors (Switzerland), 2019, doi: 10.3390/s19020383

[36] B. Xiao et al., "In-situ monitoring of a filament wound pressure vessel by the MWCNT sensor under hydraulic fatigue cycling and pressurization," Sensors (Switzerland), 2019, doi: 10.3390/s19061396

[37] M. Greenwood, “What Caused Taiwan'S Nanfang'Ao Bridge To Collapse?" 2019. [Online]. Available: https://www.engineering.com/BIM/ArticleID/19645/What-Caused-Taiwans-Nanfangao-Bridge-to-

Collapse.aspx

[38] M. M. F. Elghanudi, "Implementation of vibration-based structural health monitoring technique for identification of simulated corrosion damage in steel pipeline using neural network," 2018

[39] Z. Mohamad et al., "Classification of damage severity in natural fibre composites using principal component analysis," Int. J. Integr. Eng., 2018, doi: 10.30880/ijie.2018.10.08.023

[40] J. Sun, D. Chen, C. Li, and H. Yan, "Integration of scheduled structural health monitoring with airline maintenance program based on risk analysis," Proc. Inst. Mech. Eng. Part O J. Risk Reliab., vol. 232, no. 1, pp. 92-104, 2018, doi: 10.1177/1748006X17742777 